\title{
Metformin as Treatment for Overweight and Obese Adults: A Systematic Review
}

Kara M. Levri, MD, MPH ${ }^{1}$

Elizabeth Slaymaker, $M D^{1,2}$

Allen Last, $M D^{1}$

Julie Yeh, $M D^{1}$

Jonathan Ference, PharmD ${ }^{1,3}$

Frank D'Amico, $P b D^{1}$

Stephen A. Wilson, $M D^{1}$

'University of Pittsburgh Medical Center

St. Margaret, Pittsburgh, Pa

${ }^{2}$ Grace Medical Associates, Pittsburgh, $\mathrm{Pa}$

${ }^{3}$ University of Oklahoma-Tulsa, Tulsa, Okla

\begin{abstract}
PURPOSE We wanted to determine whether metformin is an effective medication for treatment of overweight or obese adults who do not have diabetes mellitus or polycystic ovary syndrome (PCOS).

METHODS We searched MEDLINE (1966-2003), EMBASE (1986-2003), Allied and Complementary Medicine Database (1985-2003), International Pharmaceutical Abstracts (1970-2003), the Cochrane Library, American College of Physicians Journal Club, Database of Abstracts of Reviews of Effects, Cochrane Controlled Trials Register, MEDLINE In-Process \& Other Non-Indexed Citations, reference lists of retrieved articles, and articles by selected authors and pharmaceutical manufacturers. Inclusion criteria were being obese or overweight determined by a BMI of $25 \mathrm{~kg} / \mathrm{m}^{2}$ or greater or waist-to-hip ratio (WHR) of more than 0.8 , metformin use, and aged 18 years or older. Exclusion criteria were a diagnosis of diabetes mellitus, polycystic ovarian syndrome or descriptors of polycystic ovarian syndrome, human immunodeficiency virus infection, and concomitant antipsychotic medications. Trials were graded on an 11-point Jadad scale. Only randomized controlled and blinded trials were accepted. Two reviewers independently extracted data from each trial. Primary outcomes measured were changes in $\mathrm{BMI}, \mathrm{WHR}$, and weight.
\end{abstract}

RESULTS Fifty-seven potentially relevant studies were initially identified; 48 were excluded because of lack of randomization, lack of blinding, failure to meet inclusion or exclusion criteria, inaccessible outcomes, or improper study design. Nine clinical trials met criteria for validity assessment. Four studies used the parameter of waist-to-hip ratio, 3 studies included BMI, and 8 used weight. Two of the 9 studies showed a small reduction in WHR.

CONCLUSION Insufficient evidence exists for the use of metformin as treatment of overweight or obese adults who do not have diabetes mellitus or polycystic ovary syndrome. Further studies are needed to answer this clinical question.

Ann Fam Med 2005;3:457-461. DOI: 10.1370/afm.343

\section{INTRODUCTION}

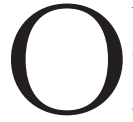

besity has become a major public health concern in the United States. More than $60 \%$ of adults are overweight or obese, ${ }^{1}$ with a body mass index (BMI) greater than $25 \mathrm{~kg} / \mathrm{m} .{ }^{2}$ Obesity affects persons regardless of age, race, ethnicity, and sex. ${ }^{2}$ It is associated annually with 400,000 deaths, and associated health care costs exceed $\$ 177$ billion. ${ }^{2}$

A combination of genetic, metabolic, behavioral, environmental, cultural, and socioeconomic factors contribute to a person's body weight. ${ }^{2}$ An elevated BMI increases the prevalence, morbidity, and mortality of type 2 diabetes mellitus, hypertension, heart disease, stroke, osteoarthritis, respiratory tract disorders, gallstones, certain types of cancer, and psychological disorders., ${ }^{2,3}$

Many treatment options are available for overweight and obese adults: behavioral strategies, medications approved by the US Food and Drug Administration (FDA), and bariatric surgery for those at greatest risk. Several FDA-approved drugs for conditions other than obesity have been 
investigated as treatment of excess body weight. ${ }^{4-7}$ Metformin is one such drug.

Metformin, the biguanide most widely used for the treatment of type 2 diabetes mellitus, ${ }^{8}$ may be useful in aiding weight loss. In diabetic patients, it suppresses endogenous glucose production and may also act as an insulin sensitizer. It also helps diabetic patients lose weight or at least keep their weight stable. ${ }^{9}$ In addition to its use in treatment of diabetes, metformin has also become commonly prescribed for patients with polycystic ovary syndrome (PCOS), and its use has resulted in weight reduction in those patients as well. ${ }^{10}$

Given the problem of increasing rates of obesity, we conducted a systematic review of the literature regarding metformin and weight loss in patients who did not have diabetes or PCOS. To our knowledge, no other systematic review has been performed on the use of metformin for weight loss in this patient population.

\section{METHODS}

MEDLINE (1966-2003), EMBASE (1986-2003), Allied and Complementary Medicine Database (AMED) (1985-2003), International Pharmaceutical Abstracts (1970-2003), the Cochrane Library, American College of Physicians (ACP) Journal Club, Database of Abstracts of Reviews of Effects (DARE), Cochrane Controlled Trials Register (CCTR), and MEDLINE InProcess \& Other Non-Indexed Citations were searched electronically. The search was limited to publications in English. Search terms were "metformin" or "Glucophage" or "biguanides" or "diguanide" and "obese/obese therapy" or "weight/weight loss" or "body fat" or "diet/ diet therapy" or "overweight" or "fitness," using appropriate suffixes and derivatives. Reference lists of all retrieved articles were examined. Attempts were made to contact authors who had expertise regarding the clinical question (ie, multiple publications on the issue), as well as the pharmaceutical manufacturer of Glucophage, Bristol-Myers Squibb, asking for additional data, unpublished studies, or missed references.

Inclusion criteria were predefined as follows: obese or overweight determined by a BMI of $25 \mathrm{~kg} / \mathrm{m}^{2}$ or greater or waist-to-hip ratio (WHR) of more than 0.8 , metformin use, and aged 18 years or older. Exclusion criteria were predefined as a diagnosis of diabetes mellitus, PCOS, or descriptors of PCOS, such as hirsutism or oligomenorrhea; infection with the human immunodeficiency virus (HIV); and concomitant antipsychotic medication use.

Articles were screened for inclusion and exclusion criteria by multiple reviewers. Authors of studies with the potential to meet inclusion or exclusion criteria by additional unpublished information were contacted.
Each trial was scored independently by 2 researchers. Trials were graded on an 11 -point Jadad scale. ${ }^{11}$ Only randomized controlled and blinded trials were accepted; no studies with a Jadad score of less than 7 were included in analysis. Studies lacking pretreatment and posttreatment weight, BMI or WHR were excluded. Disagreements were settled by group consensus.

Two reviewers independently extracted data from each trial. Primary outcomes measured were changes in BMI, WHR, and weight. All outcomes were assessed at the maximum follow-up time or the end of treatment.

No formal statistical procedures or tests were performed because there was not sufficient similar information from each article to achieve a meaningful meta-analysis.

\section{RESULTS}

Fifty-seven potentially relevant studies were initially identified. Of these, 49 were identified through a MEDLINE search, 1 from MEDLINE In-Process \& Other Non-Indexed Citations; 7 additional studies were found through a reference search of those studies. Of the studies with the potential to meet inclusion-exclusion criteria by additional unpublished information, response was achieved from 2 of the 7 authors contacted. One author was unable to provide this information because of the ongoing nature of the study. The second author was "unable to provide the time to review the sought information." The remaining 5 authors were unable to be contacted after 2 attempts. These 7 potential studies for review were among the 10 that were excluded after a more detailed evaluation and were incorporated into the category of "inaccessible outcomes" (Figure 1).

A total of 48 studies were excluded because of lack of randomization, lack of blinding, failure to meet inclusion or exclusion criteria, inaccessible outcomes, and improper study design. As a result, 9 clinical trials, ${ }^{12-20}$ published between 1970 and 2002, met criteria for validity assessment (Figure 1).

Clinical features included study durations ranging from 15 days to 1 year and metformin dosages ranged from 750 to $1700 \mathrm{mg} / \mathrm{d}$. Six of the 9 studies included both male and female participants. Four studies used the parameter of waist-to-hip ratio, 3 studies included BMI, and 8 used weight (Table 1 ).

Table 2 displays quality assessment features of the 9 clinical trials. One study specifically reported allocation concealment (Kantola et $\mathrm{al}^{16}$ ). Three studies reported intention-to-treat analysis, 3 did not utilize intentionto-treat, and 3 were not applicable for this analysis because of a lack of study dropouts.

Table 3 summarizes the quantitative results of each 


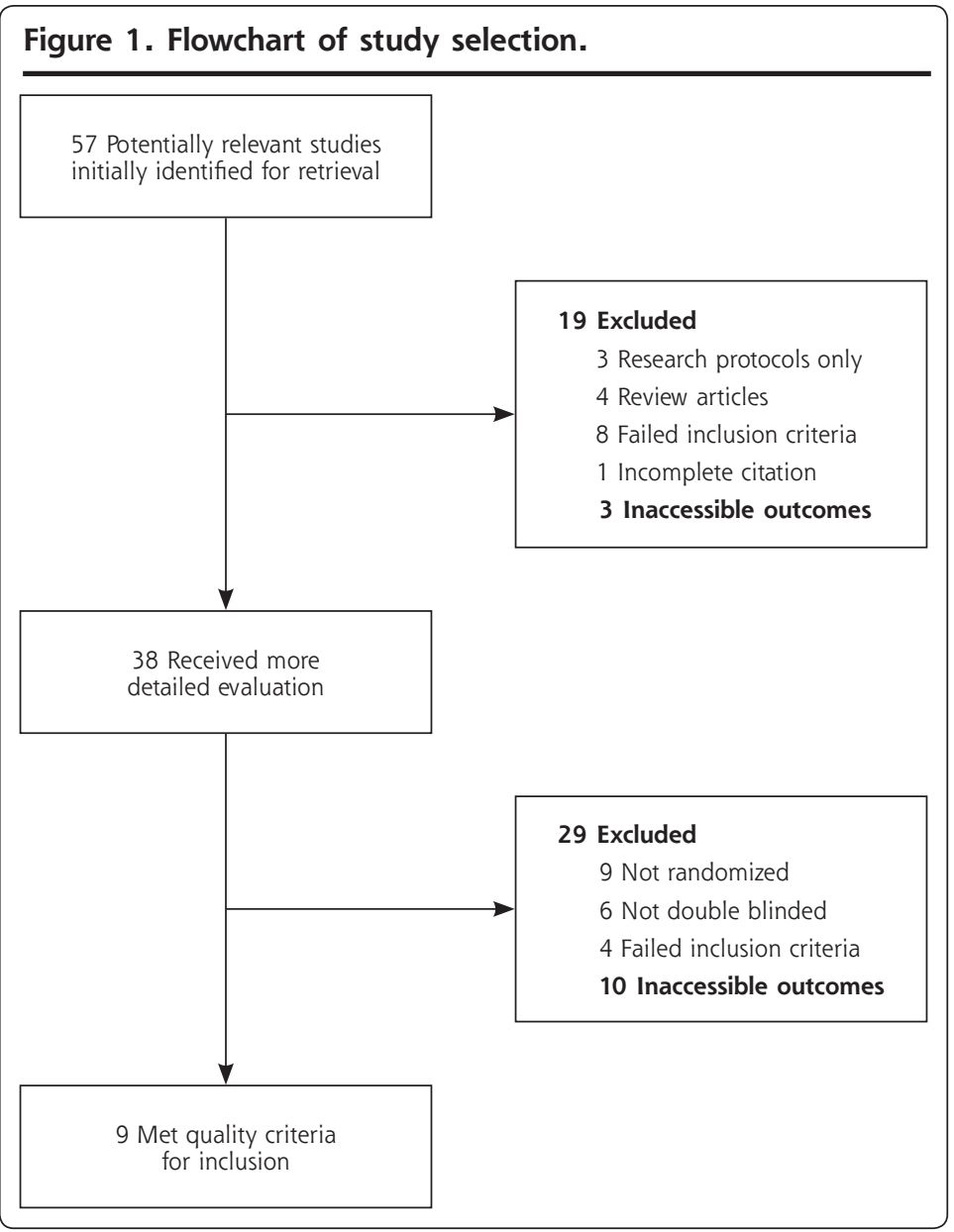

manufacturers, unpublished studies, and published trials with unpublished data. Two reviewers independently assessed each article for inclusion criteria and validity. Our failure to blind reviewers to author and journal of publication is an area that could have introduced bias; however, the reviewers did not know the authors of articles published in the journals.

The primary limitation of this systematic review is that 5 of the 9 studies were not specifically designed to study weight loss, change in BMI, or change in WHR as their primary outcome measure, which might have affected the ability of studies to detect a change in weight, BMI, or WHR, because the studies were powered for a different outcome (affecting sample size and treatment dose). Another concern is the short duration of treatment (15 days to 3 months) in 6 of the 9 studies. Furthermore, the BMI measurements of study participants were limited to overweight (BMI $25-29.9 \mathrm{~kg} / \mathrm{m}^{2}$ ) or grade I obesity (BMI $30-34.9 \mathrm{~kg} / \mathrm{m}^{2}$ ). Indeed, metformin might enhance weight loss more effectively in obese patients whose BMI is greater than $35 \mathrm{~kg} / \mathrm{m}^{2}$, because that is when insulin resistance, a potential mediator of weight gain and inhibitor of weight loss, becomes more prevalent. ${ }^{21} \mathrm{~A}$ randomized controlled

of the 9 clinical trials. Two studies showed statistically significant improvements. Fontbonne et $\mathrm{al}^{14}$ found significant reduction in weight and waist-to-hip ratio; Paolisso et al $^{20}$ showed a significant decrease in weight.

\section{DISCUSSION}

Based on this review, the evidence for using metformin as treatment of overweight or obesity in adults who had no diabetes mellitus or polycystic ovary syndrome was insufficient. We reviewed articles relating to our clinical question in the absence of any other systematic review on this topic. We found 9 high-quality articles in which patients were randomized into 2 or more groups, baseline measures were taken, and subsequent measures taken at follow-up time points. Our study has both strengths and weaknesses, and further study is needed for definitive answers.

This systematic review is methodologically sound. Reviewers evaluated double-blind randomized controlled trials using doses of metformin that resulted in effects on glucose metabolism. Beyond electronic databases, we sought information from expert authors, trial designed with adequate power for the outcomes of weight loss, BMI, or WHR that compared metformin with placebo in patients with and without diabetes or polycystic ovary syndrome, stratifying for BMI measurements of 25 to 35,35 to 40 , and greater than 40 $\mathrm{kg} / \mathrm{m}^{2}$, and observed patients for at least 1 year would provide a more definitive answer to what role, if any, metformin has in assisting weight loss.

For reasons cited in the methods, a meta-analysis of the individual studies could not be performed. Various studies gave the results in terms of differences from baseline, some reported the raw means and standard deviations at each time point, others reported the percentage of change, and a few gave their results in graphical form. Three or 4 of the studies had data that could be used for meta-analysis, but the authors collectively agreed that because only 9 studies were included in the review, a meta-analysis on such a small subset of the studies was not suitable. We do not consider this lack of meta-analysis to be a limitation of the review. All of these studies had similar designs, yet the reporting of the findings is so dissimilar, they do not allow a final quantitative answer to be obtained. Researchers 


\begin{tabular}{|c|c|c|c|c|c|c|}
\hline Source & Subjects & $\begin{array}{l}\text { Dosage } \\
(\mathrm{mg})\end{array}$ & $\begin{array}{l}\text { Study } \\
\text { Duration }\end{array}$ & $\begin{array}{l}\text { Main Outcome } \\
\text { Measure }\end{array}$ & $\begin{array}{l}\text { Treatment } \\
\text { Arms }\end{array}$ & $\begin{array}{l}\text { Baseline } \\
\text { Parameters }\end{array}$ \\
\hline $\begin{array}{l}\text { Charles et al, }{ }^{12} \\
2000\end{array}$ & 168 men & 850 bid & $3 \mathrm{mo}$ & $\begin{array}{l}\text { Lipids and blood } \\
\text { pressure }\end{array}$ & 2 & $\mathrm{WHR} \geq 0.95$ \\
\hline $\begin{array}{l}\text { Charles et al, }{ }^{13} \\
1998\end{array}$ & 457 persons & 850 bid & $1 \mathrm{y}$ & Fibrinolysis & 2 & $\begin{array}{l}W H R \geq 0.95 \text { men } \\
W H R \geq 0.80 \text { women }\end{array}$ \\
\hline $\begin{array}{l}\text { Fontbonne et al, }{ }^{14} \\
\quad 1996\end{array}$ & $\begin{array}{l}108 \text { men } \\
216 \text { women }\end{array}$ & 850 bid & $1 y$ & $\begin{array}{l}\text { Metabolic parameters } \\
\text { and fat distribution }\end{array}$ & 2 & $\begin{array}{l}W H R \geq 0.95 \text { men } \\
W H R \geq 0.80 \text { women }\end{array}$ \\
\hline $\begin{array}{l}\text { Guigliano et al, }{ }^{15} \\
1993\end{array}$ & 12 women & 850 bid & 12 wk $\times 2$ & $\begin{array}{l}\text { Blood pressure and left } \\
\text { ventricular mass }\end{array}$ & 2 & BMI $34 \pm 0.9$ \\
\hline $\begin{array}{l}\text { Kantola et al, }{ }^{16} \\
2002\end{array}$ & $\begin{array}{l}15 \text { men } \\
8 \text { women }\end{array}$ & $1,500 / d$ & 8 wk & $\begin{array}{l}\text { Blood pressure and } \\
\text { insulin sensitivity }\end{array}$ & 2 & Weight $86.4-87.7$ kg \\
\hline $\begin{array}{l}\text { Lawson et al, }{ }^{17} \\
\quad 1970\end{array}$ & 34 women & 250 tid, 500 tid & $8 w k \times 4$ & Weight loss & 4 & Weight $74.5-125.5 \mathrm{~kg}$ \\
\hline $\begin{array}{l}\text { Lehtovorta et al, }{ }^{18} \\
2001\end{array}$ & $\begin{array}{l}20 \text { men } \\
20 \text { women }\end{array}$ & $500 \mathrm{bid}$ & $6 \mathrm{mo}$ & Metabolic parameters & 2 & Weight $87.8-91.0 \mathrm{~kg}$ \\
\hline $\begin{array}{l}\text { More et al, } 119 \\
1999\end{array}$ & $\begin{array}{l}11 \text { women } \\
8 \text { men }\end{array}$ & 850 bid & $6 w k \times 2$ & Glucose disposal & 2 & $\begin{array}{l}\text { BMI } 30-48.5 \mathrm{~kg} \\
\text { Weight } 79.0-159.1 \mathrm{~kg}\end{array}$ \\
\hline $\begin{array}{l}\text { Paolisso et al, }{ }^{20} \\
1998\end{array}$ & 30 persons & $500 \mathrm{bid}, 850 \mathrm{bid}$ & $15 d$ & Food intake & 2 & $\begin{array}{l}\text { WHR } 0.83 \pm 0.01 \\
\text { BMI } 33.1 \pm 6.4 \mathrm{~kg}\end{array}$ \\
\hline
\end{tabular}

Table 2. Quality Features of Articles Included for Review

\begin{tabular}{|c|c|c|c|c|c|c|c|}
\hline Source & Randomized & $\begin{array}{l}\text { Double- } \\
\text { Blinded }\end{array}$ & $\begin{array}{l}\text { Description } \\
\text { of Dropouts }\end{array}$ & Design & $\begin{array}{l}\text { Description } \\
\text { of Allocation } \\
\text { Concealment }\end{array}$ & $\begin{array}{l}\text { Power } \\
\text { Analysis }\end{array}$ & $\begin{array}{c}\text { Intention } \\
\text { to Treat }\end{array}$ \\
\hline Charles et al, ${ }^{12} 2000$ & Yes & Yes & Yes & $\mathrm{RCT}$ & Indeterminant & Yes & Yes \\
\hline Charles et al, ${ }^{13} 1998$ & Yes & Yes & Yes & $\mathrm{RCT}$ & Indeterminant & No & No \\
\hline Fontbonne et al, ${ }^{14} 1996$ & Yes & Yes & Yes & $\mathrm{RCT}$ & Indeterminant & Yes & Yes \\
\hline Guigliano et al, ${ }^{15} 1993$ & Yes & Yes & Yes & Crossover & Indeterminant & Yes & No dropouts \\
\hline Kantola et al, ${ }^{16} 2002$ & Yes & Yes & Yes & $\mathrm{RCT}$ & Yes & Yes & No \\
\hline Lawson et al, ${ }^{17} 1970$ & Yes & Yes & Yes & Crossover & Indeterminant & No & No \\
\hline Lehtovorta et al, ${ }^{18} 2001$ & Yes & Yes & Yes & $\mathrm{RCT}$ & Indeterminant & Yes & No dropouts \\
\hline More et al, ${ }^{19} 1999$ & Yes & Yes & Yes & Crossover & Indeterminant & No & Yes \\
\hline Paolisso et al,20 1998 & Yes & Yes & Yes & $\mathrm{RCT}$ & Indeterminant & No & No dropouts \\
\hline
\end{tabular}

Table 3. Results of Clinical Trials Included for Review

\begin{tabular}{|c|c|c|c|c|c|c|}
\hline \multirow[b]{2}{*}{ Source } & \multicolumn{2}{|c|}{ Weight (kg) } & \multicolumn{2}{|c|}{ BMI (kg/m²) } & \multicolumn{2}{|c|}{ Waist-Hip Ratio ${ }^{\dagger}$} \\
\hline & Metformin & Placebo & Metformin & Placebo & Metformin & Placebo \\
\hline Charles et al, ${ }^{12} 2000$ & -0.50 & 0.10 & - & - & -0.008 & -0.015 \\
\hline Charles et al, ${ }^{13} 1998$ & -2.0 & -0.8 & - & - & - & - \\
\hline Fontbonne et al, ${ }^{14} 1996$ & $-2.0 *$ & -0.8 & - & - & $-0.009 *$ & -0.017 \\
\hline Guigliano et al, ${ }^{15} 1993$ & - & - & 0 & 0 & 0 & 0 \\
\hline Kantola et al, ${ }^{16} 2002$ & -0.2 & 0.2 & - & - & - & - \\
\hline Lawson et al, ${ }^{17} 1970$ & -3.6 & -2.22 & - & - & - & - \\
\hline Lehtovorta et al, ${ }^{18} 2001$ & -2.6 & -1.2 & - & - & - & - \\
\hline More et al, ${ }^{19} 1999$ & -0.6 & 0.3 & -0.3 & 0.2 & 0.01 & 0.05 \\
\hline Paolisso et al, 201998 & $-2.8 *$ & -0.25 & -1.0 & -0.5 & 0.2 & 0.25 \\
\hline
\end{tabular}


can improve the quality of randomized controlled trials by following guidelines for reporting data. ${ }^{22,23}$

Evidence is insufficient to conclude that metformin can serve as a treatment of overweight or grade I obesity in adults who do not have diabetes mellitus or polycystic ovary syndrome. At this time, the use of metformin is not recommended as treatment of these conditions. If clinicians and patients are considering pharmacologic assistance for weight loss, the National Heart, Lung, and Blood Institute and Cochrane Reviews ${ }^{24,25}$ recommend sibutramine or orlistat as therapeutic options for patients who have a BMI of greater than 30 and who have no concomitant risk factors and for patients who have a BMI greater than 27 and who have concomitant risk factors; they recommend bariatric surgery as a therapeutic option for patients who have a BMI greater than 40 .

To read or post commentaries in response to this article, see it online at http://www.annfammed.org/cgi/content/full/3/5/457.

Key words: Metformin; obesity; anti-obesity agents; body mass index

Submitted October 4, 2004; submitted, revised, April 19, 2005; accepted April 28, 2005.

A version of this report has been presented as "Metformin as Treatment for Overweight or Obese Adults: a Systematic Review," as a research in progress poster presentation at the 37th Society of Teachers of Family Medicine Annual Spring Conference, Toronto, Ontario, May 2004; as "Metformin as Treatment for Overweight or Obese Adults: a Systematic Review," at the Pennsylvania Academy of Family Physicians Research Day, Philadelphia, Pa, April 2004; as "Metformin as Treatment for Overweight or Obese Adults: a Systematic Review," as a UPMC St. Margaret Fellowship Research Day presentation, UPMC St. Margaret, Pittsburgh, Pa, June 2004; and as "Metformin as Treatment for Overweight or Obese Adults: a Systematic Review," as a research in progress poster presentation at the 38th Society of Teachers of Family Medicine Annual Spring Conference, New Orleans, La, May 2005.

Funding support: University of Pittsburgh Medical Center St. Margaret, Pittsburgh, Pa.

\section{References}

1. National Center for Health Statistics, Hyattsville, Md. Prevalence of overweight or obesity among adults: United States. Health E-Stats, 2000. 1999. Available at: http://www.cdc.gov/nccdphp/factsheets/ death_causes2000.htm. Accessed: May 19, 2004,

2. US Department of Health and Human Services. The Surgeon General's Call to Action to Prevent and Decrease Overweight and Obesity. Washington, DC, 2004. Available at: http://www.surgeongeneral.gov/ topics/obesity/calltoaction/fact_glance.htm. Accessed: May 19, 2004,

3. Overweight, obesity, and health risk. National Task Force on the Prevention and Treatment of Obesity. Arch Intern Med. 2000;160:898-904.

4. Anderson JW, Greenway FL, Fujioka K, et al. Bupropion SR enhances weight loss: a 48-week double-blind, placebo- controlled trial. Obes Res. 2002;10:633-641.

5. Moore R, Grant AM, Howard AN, Mills IH. Treatment of obesity with triiodothyronine and a very-low-calorie liquid formula diet. Lancet. 1980;1:223-226.
6. Goldstein DJ, Rampey AH, Jr., Enas GG, et al. Fluoxetine: a randomized clinical trial in the treatment of obesity. Int J Obes Relat Metab Disord. 1994;18:129-135.

7. Shapira NA, Goldsmith TD, McElroy SL. Treatment of binge-eating disorder with topiramate: a clinical case series. J Clin Psychiatry. 2000;61:368-372.

8. Bailey CJ. Biguanides and NIDDM. Diabetes Care. 1992;15:755-772.

9. Lee A, Morley JE. Metformin decreases food consumption and induces weight loss in subjects with obesity with type II non-insulindependent diabetes. Obes Res. 1998;6:47-53.

10. Pasquali R, Gambineri A, Biscotti D, et al. Effect of long-term treatment with metformin added to hypocaloric diet on body composition, fat distribution, and androgen and insulin levels in abdominally obese women with and without the polycystic ovary syndrome. J Clin Endocrinol Metab. 2000;85:2767-2774.

11. Jadad AR, Moore RA, Carroll D, et al. Assessing the quality of reports of randomized clinical trials: is blinding necessary? Control Clin Trials. 1996;17:1-12.

12. Charles MA, Eschwege E, Grandmottet $P$, et al. Treatment with metformin of non-diabetic men with hypertension, hypertriglyceridaemia and central fat distribution: the BIGPRO 1.2 trial. Diabetes Metab Res Rev. 2000;16:2-7

13. Charles MA, Morange $P$, Eschwege $E$, et al. Effect of weight change and metformin on fibrinolysis and the von Willebrand factor in obese nondiabetic subjects: the BIGPRO1 Study. Biguanides and the Prevention of the Risk of Obesity. Diabetes Care. 1998;21:1967-1972.

14. Fontbonne A, Charles MA, Juhan-Vague I, et al. The effect of metformin on the metabolic abnormalities associated with upper-body fat distribution. BIGPRO Study Group. Diabetes Care. 1996;19:920-926.

15. Giugliano D, De Rosa N, Di Maro G, et al. Metformin improves glucose, lipid metabolism, and reduces blood pressure in hypertensive, obese women. Diabetes Care. 1993;16:1387-1390.

16. Kantola I, Rouru J, Malminiemi K, Arkkila P, Huupponen R. Effect of metformin on blood pressure-A study in obese non-diabetic patients with hypertension. Clinical Drug Investigation. 2002;22:347-354.

17. Lawson AA, Strong JA, Peattie P, Roscoe P, Gibson A. Comparison of fenfluramine and metformin in treatment of obesity. Lancet. 1970;2:437-441.

18. Lehtovirta M, Forsen B, Gullstrom M, et al. Metabolic effects of metformin in patients with impaired glucose tolerance. Diabet Med. 2001;18:578-583.

19. Morel Y, Golay A, Perneger T, et al. Metformin treatment leads to an increase in basal, but not insulin-stimulated, glucose disposal in obese patients with impaired glucose tolerance. Diabet Med. 1999;16:650-655.

20. Paolisso G, Amato L, Eccellente R, et al. Effect of metformin on food intake in obese subjects. Eur J Clin Invest. 1998;28:441-446.

21. Dixon JB, O'Brien P. A disparity between conventional lipid and insulin resistance markers at body mass index levels greater than 34 kg/m(2). Int J Obes Relat Metab Disord. 2001;25:793-797

22. Moher D, Schultz K, Altman D. CONSORT (Consolidated Standards of Reporting Trials) statement. Revised recommendations for improving the quality of reports of parallel group randomized trials. Ann Intern Med 2001;134:657-662.

23. Moher D, Cook DJ, Eastwood S, et al. Improving the quality of reports of meta-analyses of randomised controlled trials: the QUOROM statement. Quality of Reporting of Meta-analyses. Lancet. 1999:354:1896-1900.

24. National Institutes of Health, National Heart, Lung, and Blood Institute. Clinical Guidelines on the Identification, Evaluation, and Treatment of Overweight and Obesity in Adults: The Evidence Report. Available at: http://www.nhlbi.nih.gov/guidelines/obesity/ob_gdlns. htm. Accessed: April 13, 2005,

25. Padwal R, Li SK, Lau DC. Long-term pharmacotherapy for obesity and overweight. Cochrane Database Syst Rev. 2003:CD004094. 